OPEN ACCESS

Edited by:

Allen Frederic Ryan,

University of California,

San Diego,

United States

Reviewed by:

Jian Dong Li,

Georgia State University,

United States

Anke Leichtle,

Universität zu Lübeck

Germany

${ }^{*}$ Correspondence:

Pratik P. Vikhe

p.vikhe@har.mrc.ac.uk

Specialty section: This article was submitted to

Genetic Disorders,

a section of the journal

Frontiers in Genetics

Received: 24 July 2019 Accepted: 16 January 2020 Published: 11 February 2020

Citation: Vikhe PP, Tateossian H, Bharj G, Brown SDM and Hood DW (2020)

Mutation in Fbxo11 Leads to Altered Immune Cell Content in Jeff Mouse Model of Otitis Media.

Front. Genet. 11:50.

doi: 10.3389/fgene.2020.00050

\section{Mutation in Fbx011 Leads to Altered Immune Cell Content in Jeff Mouse Model of Otitis Media}

\author{
Pratik P. Vikhe , Hilda Tateossian, Gurpreet Bharj, Steve D.M. Brown and Derek W. Hood \\ Mammalian Genetics Unit, MRC Harwell Institute, Oxfordshire, United Kingdom
}

The Jeff mouse mutant carries a mutation in the F-box only 11 gene (Fbxo11) and heterozygous animals display conductive deafness due to the development of otitis media (OM). The Fbxo11 locus is also associated with chronic otitis media with effusion (COME) and recurrent OM in humans. The Jeff mutation affects the ability of FBXO11 to stabilize p53 that leads to perturbation in the TGF-beta/Smad2 signaling pathway important in immunity and inflammation. In the current study, we evaluated the effect of the Jeff mutation on the immune cell content using multicolor flow cytometry. In blood of Jeff heterozygotes, we observed a significant increase in the number of $\mathrm{NK}$, dendritic (CD11b+), neutrophils, and natural killer $\mathrm{T}$ (NKT) cells and a significant decrease in effector T-helper and B-lymphocytes compared to wild-type controls. The percentage of NK cells significantly decreased in the lungs of Jeff heterozygotes, with a concomitant reduction in B-lymphocytes and T-cytotoxic cells. In the spleen, Jeff heterozygotes displayed a significant decrease in mature B-lymphocytes, effector T-helper, and naïve T-cytotoxic cells. Neutrophils, dendritic, and NKT cells dominated bulla fluid in Jeff heterozygote mice. Similar analysis carried out on Fbxo $11^{\text {tm2b/+ }}$ heterozygotes, which carry a null allele, showed no difference when compared to wild-type. Cytokine/chemokine analysis revealed a significant increase in the G-CSF, GM-CSF, sTNFRI, TPO, and IL-7 levels in Jeff heterozygote serum compared to wild-type. This analysis increases our understanding of the role played by Fbxo11, a gene associated with human $\mathrm{OM}$, in the systemic and localized cellular immune response associated with increased susceptibility to OM.

Keywords: Fbxo11, otitis media, Jeff mouse, immune cells, natural killer cells

\section{INTRODUCTION}

Otitis media $(\mathrm{OM})$ is a very common middle ear disease in children that is characterized by middle ear inflammation and fluid accumulation (Schilder et al., 2016). Pathology of OM can manifest in different ways and chronic and recurrent OM (ROM), often accompanied by effusion (chronic OM with effusion, COME), can lead to hearing loss and developmental delays with a significant burden on the healthcare system (Veenhoven et al., 2003). Tympanostomy to alleviate COME remains the commonest cause of surgery in children. There is a significant genetic component to COME (Sale et al., 2011), and recently the discovery of a number of mouse genetic models of COME has led to 
insights into the genetic and molecular pathways involved in the pathophysiology of chronic middle ear disease (Li et al., 2013; Bhutta et al., 2017b). Jeff (Hardisty et al., 2003), Junbo (Parkinson et al., 2006), and edison (Crompton et al., 2017) mutants are COME mouse models each with single point mutation in the Fbxo11, Evi1, and nischarin genes respectively, identified at MRC Harwell through a deafness screen as a part of a larger scale Nethyl-N-nitrosourea (ENU) mouse mutagenesis program (Nolan et al., 2000).

Following the identification of a number of genes involved in COME in the mouse there have been several studies to explore the association of these genes with COME in the human population. Association studies have shown that several human genes may increase susceptibility toward OM, including FBXO11 (Sale et al., 2011). One of the largest association studies employing samples from 1,296 families (3,828 individuals) uncovered a significant link between FBXO11 and OM susceptibility (Bhutta et al., 2017a). Moreover, two similar studies carried out on western Australian children (Rye et al., 2011) and Minnesota COME/ROM families (Segade et al., 2006) showed a direct link between polymorphisms at the FBXO11 locus and OM susceptibility.

FBXO11 is part of the SCF (SKP1-cullin-F-box) complex, a multi-protein E3 ubiquitin-ligase complex catalyzing the ubiquitination of proteins destined for proteasomal degradation. FBXO11 is involved in ubiquitination of BCL6 (Duan et al., 2012) and phosphorylated SNAIL (Zheng et al., 2014), and neddylation of p53 (Abida et al., 2007), which play critical roles in regulation of the mammalian cell cycle and function. FBXO11, through regulation of BCL6, modulates Bcell survival and plays a crucial role in B-cell lymphoma (Duan et al., 2012). Other than regulation of B-cell survival in lymphoma, the role played by FBXO11 in modulating other immune cells and the relevance of this to OM remains unclear.

In the current study, we used the well-characterized COME Jeff mouse model (Hardisty et al., 2003; Hardisty-Hughes et al., 2006) which carries a missense mutation in the Fbxo11 gene. The homozygotes of this mutant mouse line do not survive beyond birth and show a severe lung phenotype (Tateossian et al., 2009), whereas the heterozygote mice survive with chronic OM (Hardisty et al., 2003). FBXO11 can function as a Nedd8-ligase for p53 promoting its neddylation and inhibiting its transcription activity. The Fbxo11 mutation in the Jeff mouse results in a decreased level of p53 and increased pSmad2 levels; pSmad2 is directly involved in the regulation of the TGF-beta pathway (Tateossian et al., 2009; Tateossian et al., 2015). The TGF-beta pathway plays a critical role in maintaining homeostasis by regulating remodeling of injury in disease and modulating the immune and inflammatory response (Wan and Flavell, 2007).

The association of FBXO11 locus polymorphisms with OM in the human population and the corresponding phenotype observed in the Jeff mouse with a mutation in the orthologous gene makes it a vital model to dissect important immune changes that are associated with OM. In the current study, we analyzed the cellular immune changes that occur due to the Fbxol1 mutation in the heterozygote Jeff mouse using a comprehensive flow cytometry panel that classified granulocytes, monocytes, macrophages, eosinophils, dendritic, natural killer, B and T cells. The Jeff mutation significantly altered the immune cell content in the blood, mostly affecting the natural killer cells, and adaptive B and $\mathrm{T}$ immune cells, which underlines the significance of FBXO11 in the immune/genetic regulation of these cells. Further, we carried out a similar analysis with the heterozygote Fbxo11 knockout mouse in order to better understand the role of FBXO11 in the cellular immune response. The Fbxo11 knockout mouse did not show significant differences in the immune cells as was observed in the Jeff mouse, suggesting that the Fbxo11 mutation in the Jeff mouse has gain of function effects that lead to altered immune cell content. Also, using a mouse model, this study is the first to report systemic immune cell differences due to a genetic aberration leading to localized middle ear inflammation and OM.

\section{MATERIALS AND METHODS}

\section{Mice}

The humane care and use of mice in this study was carried out under the appropriate UK Home Office license and the local ethics review committee reviewed the experimental procedures.

Heterozygote $\mathrm{Fbxo11}{ }^{\mathrm{Jf} / \mathrm{+}}$ (also referred to as Jeff Het) mice and their Jeff wild-type littermates (also referred to as Jeff $\mathrm{Wt}$ ) were generated by inter-crossing F1 Fbxo $11^{\mathrm{Jf} /+} \mathrm{C} 57 \mathrm{BL} / 6 \mathrm{~J} \mathrm{C} 3 \mathrm{H} / \mathrm{HeH}$ males with $\mathrm{F} 1 \mathrm{Fbxo11}^{+/+} \mathrm{C} 57 \mathrm{BL} / 6 \mathrm{~J} \mathrm{C} 3 \mathrm{H} / \mathrm{HeH}$ wild-type females. Heterozygote Fbxo11 ${ }^{\text {tm } 2 b /+}$ (also referred to as Fbxo11 knockout) and their $\mathrm{Fbxol1}^{+/+}$wild-type littermates were generated by inter-crossing F1 Fbxo11 $1^{\text {tm } 2 b /+}$-PL-TM2B-C57BL/6NJ with $\mathrm{C} 57 \mathrm{BL} / 6 \mathrm{NJ}$ females. The mice were specific pathogen free and used at 8 weeks of age.

\section{Sample Preparation}

Blood was collected by retro-orbital bleeding under terminal anesthesia induced by an intraperitoneal overdose of sodium pentobarbital in lithium heparin tubes. For flow cytometry analysis, $50 \mu \mathrm{l}$ of blood was resuspended in $1 \mathrm{ml}$ of red blood cell (RBC) lysis buffer (Biolegend ${ }^{\mathrm{TM}}$ ) for $10 \mathrm{~min}$ on ice followed by centrifugation and two washes with $1 \mathrm{ml}$ phosphate buffer saline (PBS). The final pellet was resuspended in FACS buffer ( 5 $\mathrm{mM}$ EDTA, $0.5 \%$ fetal calf serum in PBS). Middle ear fluid for flow cytometry and cytokine/chemokine analyses was collected as described previously (Vikhe et al., 2019). Briefly, middle ear fluid was collected from unskinned heads obtained from mice under terminal anesthesia. After removal of any material on the external surface of the tympanic membrane, a hole was made in the membrane while removing the malleus from the middle ear using a sterile pair of forceps and fluid was collected with a pipette and microtip in $10 \mu \mathrm{l}$ cold PBS. Other tissues (spleens and lungs) were collected in gentleMACS ${ }^{\mathrm{TM}} \mathrm{C}$ tubes with $3 \mathrm{ml}$ RPMI supplemented with $10 \mu \mathrm{g} / \mathrm{ml}$ collagenase II (Serlabo ${ }^{\mathrm{TM}}$ ) and 166 $\mu \mathrm{g} / \mathrm{ml}$ DNAse I (Sigma ${ }^{\mathrm{TM}}$ ). The tissue was homogenized in a gentleMACS ${ }^{\mathrm{TM}}$ Dissociator and the single cell suspension was 
separated from tissue debris by passing through a $70 \mu \mathrm{m}$ Cell Strainer. The cell pellet obtained after centrifugation at $800 \mathrm{x} \mathrm{g}$ for 2 min was resuspended in RBC lysis buffer. Finally, after RBC lysis, the cells were pelleted by centrifugation then resuspended in FACS buffer for flow cytometry analysis.

\section{Flow Cytometry Analysis}

Middle ear fluid, blood, lung, and spleen samples were diluted with FACS buffer, and a cell count was obtained. The samples were transferred to a 96 well plate at the concentration of $2 \times 10^{5}$ cells/well. Cells were centrifuged and washed twice with FACS buffer. For the analysis of different types of immune cells, the resuspended cells were incubated for 15 min with CD16/CD32 antibody (BD Pharmagen ${ }^{\mathrm{TM}}$ ) at a dilution of 1:100. After centrifugation at $800 \mathrm{x} \mathrm{g}$ for $1 \mathrm{~min}$, cell pellets were resuspended in $100 \mu \mathrm{l}$ of either of panel 1 or panel 2 (Table S1) antibody cocktail and incubated for $20 \mathrm{~min}$ in the dark. Cells were centrifuged and washed twice with FACS buffer and finally resuspended in $100 \mu \mathrm{l}$ of Sytox DNA stain (1:10,000). After making up the final volume to $250 \mu \mathrm{l}$ with FACS buffer, flow cytometry was performed using a BD FACSCanto ${ }^{\mathrm{TM}}$ II system. FlowJo software (Tree StarTM) was used to analyze the data obtained (Figures S1, S2 and Table S2).

\section{Cytokine/Chemokine Analysis}

Cytokine and chemokine levels were measured using a mouse cytokine antibody array (Mouse Cytokine Array C1, RayBiotech Inc. ${ }^{\mathrm{TM}}$ ) as described previously (Vikhe et al., 2019). Changes in IL-7 and IL-15 were analyzed by Mouse IL-7 and IL-15 DuoSet ELISA (R\&D systems ${ }^{\mathrm{TM}}$ ) according to the manufacturer's instructions. The color change was measured at $450 \mathrm{~nm}$ on an Epoch BioTek ${ }^{\mathrm{TM}}$ plate reader and the IL-7 and IL-15 concentrations were calculated by using the standard curve obtained.

\section{Data Analysis}

We used the unpaired test assuming equal variance for comparing the cytokine/chemokine changes between $\mathrm{Fbxo1} 11^{\mathrm{Jf}+\mathrm{+}}$ serum to the Jeff wild-type whereas non-parametric MannWhitney $\mathrm{U}$ test was used to compare the flow cytometry data. A $P$ value of less than 0.05 was considered significant.

\section{RESULTS}

\section{Innate Immune Cell Population in Fbx011 ${ }^{\mathrm{Jf} /+}$ Mouse}

Innate immune cells play a critical role in the initiation of the inflammatory response and the onset and maintenance of OM (Mittal et al., 2014). The Fbxo11 $1^{\mathrm{Jf} /+}$ mouse is characterized by middle ear inflammation that mimics the human OM and also exhibits a defective lung phenotype (Tateossian et al., 2009). To understand the effect of the Jeff mutation in the Fbxo11 gene on the innate immune cell population we analyzed the neutrophils, eosinophils, macrophages, monocytes, dendritic cells (DC) $(\mathrm{CD} 11 \mathrm{~b}+\mathrm{ve}$ and $-\mathrm{ve})$, progenitor DC, and natural killer (NK) cells present in blood, spleen, lungs, and middle ear fluids obtained from the Fbxo11 $\mathrm{Jf/+}$ mouse (Table 1). Significant differences were observed in the proportion of blood neutrophils, macrophages, DCs, and NK cells in Fbxo $11^{\mathrm{Jf/+}}$

TABLE 1 | Immune cell percentage in Jeff wild-type (Jeff Wt) and Fbxo $11^{\mathrm{Jf} / \mathrm{t}}$ (Jeff Het) mouse obtained by flow cytometry.

\begin{tabular}{|c|c|c|c|c|c|c|c|}
\hline \multirow[t]{2}{*}{ Immune cells } & \multicolumn{2}{|c|}{ Blood } & \multicolumn{2}{|c|}{ Lungs } & \multicolumn{2}{|c|}{ Spleen } & \multirow{2}{*}{$\begin{array}{c}\text { MEF } \\
\text { Jeff Het }\end{array}$} \\
\hline & Jeff Wt & Jeff Het & Jeff Wt & Jeff Het & Jeff Wt & Jeff Het & \\
\hline Granulocytes & $16.60( \pm 1.76)$ & $19.30( \pm 0.85)$ & $6.21( \pm 0.79)$ & $5.34( \pm 0.43)$ & $3.53( \pm 0.43)$ & $2.77( \pm 0.31)$ & $10.34( \pm 4.11)$ \\
\hline Eosinophils & $0.18( \pm 0.07)$ & $0.29( \pm 0.05)$ & $0.035( \pm 0.01)$ & $0.028( \pm 0.01)$ & $0.05( \pm 0.03)$ & $0.021( \pm 0.01)$ & $0.14( \pm 0.05)$ \\
\hline Macrophages & $0.20( \pm 0.06)$ & $0.57( \pm 0.16)$ & $0.21( \pm 0.04)$ & $0.22( \pm 0.03)$ & $0.34( \pm 0.04)$ & $0.23( \pm 0.02)$ & $0.22( \pm 0.06)$ \\
\hline Monocytes & $5.54( \pm 0.88)$ & $8.41( \pm 1.55)$ & $1.58( \pm 0.21)$ & $0.81( \pm 0.22)$ & $0.89( \pm 0.03)$ & $0.84( \pm 0.12)$ & $0.34( \pm 0.16)$ \\
\hline DC CD8 type & $27.5( \pm 2.78)$ & $20.44( \pm 2.19)$ & $13.52( \pm 1.53)$ & $13.17( \pm 1.43)$ & $43.60( \pm 0.70)$ & $42.30( \pm 1.58)$ & $3.69( \pm 0.72)$ \\
\hline DC CD11b type & $1.29( \pm 0.28)$ & $3.31( \pm 0.53)$ & $1.06( \pm 0.15)$ & $1.35( \pm 0.13)$ & $1.81( \pm 0.17)$ & $1.92( \pm 0.11)$ & $4.54( \pm 0.99)$ \\
\hline Progenitor DC (pDC) & $7.54( \pm 1.96)$ & $7.99( \pm 1.06)$ & $10.65( \pm 0.89)$ & $11.13( \pm 1.36)$ & $5.43( \pm 0.75)$ & $4.50( \pm 0.43)$ & $6.69( \pm 1.46)$ \\
\hline NK cells & $5.87( \pm 0.72)$ & $10.84( \pm 1.71)$ & $2.80( \pm 0.17)$ & $0.91( \pm 0.23)$ & $4.09( \pm 0.63)$ & $3.12( \pm 0.20)$ & $0.79( \pm 0.35)$ \\
\hline T helper (Th) effector & $2.63( \pm 0.72)$ & $0.69( \pm 0.03)$ & $0.37( \pm 0.13)$ & $0.17475( \pm 0.12)$ & $1.28( \pm 0.06)$ & $0.72( \pm 0.01)$ & $0.22( \pm 0.07)$ \\
\hline T helper (Th) resting & $4.49( \pm 0.59)$ & $4.54( \pm 0.68)$ & $2.45( \pm 0.50)$ & $1.22( \pm 0.32)$ & $7.73( \pm 0.71)$ & $8.93( \pm 0.61)$ & $0.16( \pm 0.07)$ \\
\hline $\mathrm{T}$ regulator (T reg) effector & $0.86( \pm 0.08)$ & $0.66( \pm 0.06)$ & $0.68( \pm 0.12)$ & $0.52( \pm 0.12)$ & $0.53( \pm 0.05)$ & $0.46( \pm 0.03)$ & $0.28( \pm 0.08)$ \\
\hline $\mathrm{T}$ regulator (T reg) resting & $0.14( \pm 0.02)$ & $0.43( \pm 0.06)$ & $0.35( \pm 0.06)$ & $0.22( \pm 0.07)$ & $0.82( \pm 0.01)$ & $1.34( \pm 0.09)$ & $0.029( \pm 0.01)$ \\
\hline T cytotoxic effector & $0.47( \pm 0.09)$ & $0.31( \pm 0.01)$ & $0.31( \pm 0.10)$ & $0.11( \pm 0.03)$ & $0.53( \pm 0.08)$ & $0.34( \pm 0.03)$ & $0.68( \pm 0.27)$ \\
\hline T cytotoxic naive & $3.62( \pm 0.67)$ & $2.53( \pm 0.38)$ & $1.25( \pm 0.12)$ & $0.58( \pm 0.12)$ & $5.56( \pm 0.73)$ & $6.92( \pm 0.72)$ & $0.07( \pm 0.04)$ \\
\hline T cytotoxic resting & $1.56( \pm 0.35)$ & $0.67( \pm 0.12)$ & $0.44( \pm 0.07)$ & $0.10( \pm 0.03)$ & $2.44( \pm 0.25)$ & $1.64( \pm 0.17)$ & $0.04( \pm 0.02)$ \\
\hline B2 total & $24.82( \pm 2.80)$ & $11.16( \pm 1.22)$ & $11.53( \pm 1.09)$ & $9.22( \pm 0.91)$ & $34.90( \pm 1.07)$ & $28.87( \pm 0.95)$ & $1.37( \pm 0.34)$ \\
\hline B2 mature & $2.31( \pm 0.25)$ & $1.55( \pm 0.09)$ & $2.69( \pm 0.48)$ & $3.75( \pm 0.27)$ & $3.38( \pm 0.28)$ & $2.97( \pm 0.09)$ & $0.26( \pm 0.11)$ \\
\hline B2 immature & $21.98( \pm 2.79)$ & $9.26( \pm 1.13)$ & $8.52( \pm 0.85)$ & $5.14( \pm 0.70)$ & $30.67( \pm 0.91)$ & $25.20( \pm 0.83)$ & $1.03( \pm 0.23)$ \\
\hline B1 total & $0.73( \pm 0.09)$ & $0.58( \pm 0.03)$ & $3.14( \pm 0.48)$ & $5.81( \pm 0.76)$ & $3.43( \pm 0.38)$ & $4.90( \pm 0.44)$ & $1.74( \pm 0.32)$ \\
\hline NKT effector & $0.77( \pm 0.14)$ & $2.04( \pm 0.27)$ & $12.92( \pm 0.88)$ & $16.22( \pm 2.22)$ & $1.29( \pm 0.18)$ & $0.95( \pm 0.07)$ & $3.15( \pm 0.99)$ \\
\hline Invariant NKT (iNKTs) & $0.57( \pm 0.07)$ & $2.23( \pm 0.33)$ & $6.21( \pm 1.09)$ & $8.98( \pm 1.40)$ & $1.13( \pm 0.24)$ & $1.47( \pm 0.15)$ & $1.99( \pm 0.67)$ \\
\hline NKT resting & $0.46( \pm 0.05)$ & $1.43( \pm 0.16)$ & $0.96( \pm 0.11)$ & $1.43( \pm 0.35)$ & $0.78( \pm 0.11)$ & $1.63( \pm 0.20)$ & $0.68( \pm 0.17)$ \\
\hline
\end{tabular}

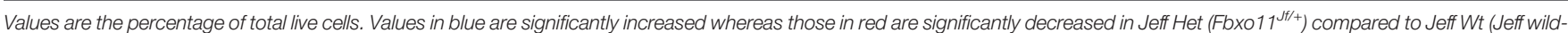
type) mice. MEF, middle ear fluid; DC, dendritic cell; NK, natural killer cell. 
when compared to the Jeff wild-type litter mates. The greatest difference was observed in blood NK cell levels, which were $10.84 \%$ of live cells in the Fbxo $11^{\mathrm{Jf} /+}$ mouse compared to $5.87 \%$ in the Jeff wild-type counterpart (Figure 1A-C). The Fbxo $11^{J f /+}$ mouse had $3.31 \%$ of CD11b+ve DCs compared to $1.29 \%$ present in Jeff wild-type blood. Similarly, slight but significantly higher levels of macrophages $(0.57 \%)$ were observed in Fbxo $11^{\mathrm{Jf} /+}$ compared to $0.20 \%$ in Jeff wild-type blood. Blood granulocyte levels were significantly higher in the Fbxo $11^{\mathrm{Jf} /+}(19.30 \%)$ compared to Jeff wild-type (16.60\%) mouse. In contrast to blood, a significantly lower proportion of NK cells was observed in lungs of Fbxo11 $1^{J f /+}(0.91 \%)$ compared to Jeff wildtype $(2.80 \%)$ mice. Further, Fbxo $11^{\mathrm{Jf} /+}$ lungs had $0.81 \%$ of monocytes compared to $1.58 \%$ in the Jeff wild-type mouse. No significant difference was observed in $\mathrm{Fbxo1} 1^{\mathrm{Jf} /+}$ spleen innate immune cells when compared to the Jeff wild-type mouse. The middle ear fluid from Fbxo $11^{J f /+}$ had a high percentage of granulocytes and DCs. The middle ear fluid comprised $10.34 \%$ neutrophils and $6.69 \%$ progenitor dendritic cells (pDCs). Compared to pDC's, the percentage of CD11b-ve DCs and $\mathrm{CD} 11 \mathrm{~b}+\mathrm{DCs}$ in the Fbxo11 $1^{\mathrm{Jf} /+}$ middle ear fluid was less: 3.69 and $4.54 \%$ respectively (Table $\mathbf{1}$ ).

A similar analysis carried out on the Fbxo $11^{\mathrm{tm} 2 b /+}$ heterozygote Fbxo11 knockout mouse (Table S3), did not show the major differences in innate immune cell content as observed in the Fbxo11 $1^{\mathrm{Jfl}+}$ mouse in comparison to their respective wild-type countertypes. The only significant difference observed for the Fbxo $11^{t m 2 b /+}$ compared to Fbxo $11^{+/+}$mouse was for blood and lung macrophages and blood CD11b+ DC's. Fbxo11 $1^{\text {tm } 2 b /+}$ had a slight but significantly higher percentage of blood macrophages (1.72\%) compared to the Fbxo11 $1^{+/+}$mouse (0.95\%). Also, CD11b+ DC's were $3.61 \%$ in Fbxo11 $1^{\text {tm } 2 b /+}$ mouse compared to $2.65 \%$ in the $\mathrm{Fbxo}_{1} 1^{+/+}$ mouse blood. In lungs of the Fbxo $11^{\text {tm } 2 b /+}$ mouse, macrophage numbers were significantly elevated $(0.86 \%)$ compared to its wild-type counterpart, Fbxo11 $1^{+/+}(0.39 \%)$. We observed minor
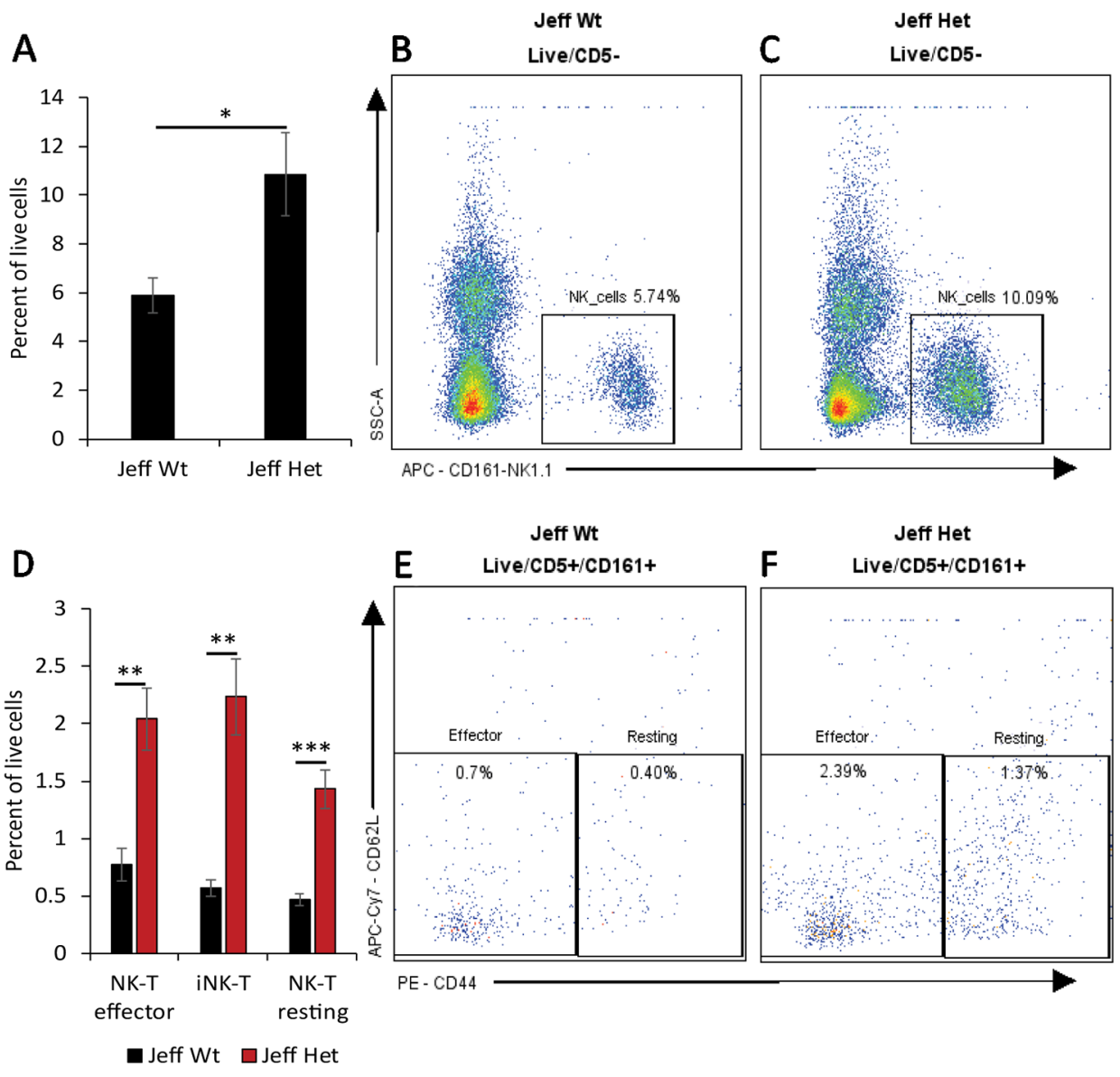

FIGURE 1 | Natural killer (NK) cell percentage in Jeff mice (Fbxo $11^{\mathrm{Jf} / \mathrm{t}}$ and Jeff Wt). (A) Average difference in the percentage of blood NK cells in Jeff Het (Fbxo $11^{\mathrm{Jf} / \mathrm{t}}$ ) and Jeff wild type (Jeff Wt) mice. The error bars show standard error of mean where $n=4$ and ${ }^{*} P<0.05$. Representative flow cytometry plot for NK cell analysis of bloods from Jeff Wt (B) and Jeff Het (Fbxo1 ${ }^{J / /+}$ ) (C) mice. (D) Average difference in the percentage of blood effector NKT, resting NKT, and invariant NKT (iNKT) cells in Jeff Het $\left(\mathrm{FbxO} 11^{\mathrm{Jf} /+}\right)$ and Jeff Wt mice. The error bars show standard error of mean where $n=4$ and ${ }^{*} \mathrm{P}<0.05,{ }^{* *} \mathrm{P}<0.01,{ }^{* * *} \mathrm{P}<0.001$. Representative flow cytometry plot for NKT cell analysis of bloods from Jeff Wt (E) and Jeff Het $\left(F b \times 011^{\mathrm{Jf} / \mathrm{H}}\right)$ (F) mice. 
immune cell differences between the Jeff wild-type and $\mathrm{Fbxo11}^{+/+}$ wild-type mice. It is known that mouse background affects immunity and the mouse immune response to infection. The Jeff wild-type and $\mathrm{FbxoI1}^{+/+}$mouse vary in their background: Jeff wild-type is on mixed $\mathrm{C} 57 \mathrm{BL} / 6 \mathrm{~J} \mathrm{C} 3 \mathrm{H} / \mathrm{HeH}$ background whereas the $\mathrm{Fbxo11} \mathrm{1}^{+/+}$mouse is on a C57BL/6NJ background, we predict that this difference in background could be influencing the difference in immune cell content observed between these wild-types.

Our observed differences in innate immune cells between the Fbxo11 $1^{\mathrm{ffl+}}$ and the Fbxo11 ${ }^{\mathrm{tm} 2 \mathrm{~b} /+}$ mouse indicates the significant role played by the Fbxo11 gene in immunogenetic control of these cells and OM.

\section{Adaptive Immune Cell Population in Jeff Mouse}

We characterized the content of adaptive immune cells (Table 1): $\mathrm{T}$ cells (helper and cytotoxic), B cells, and natural killer T (NKT) cells in Fbxo11 ${ }^{\mathrm{Jf} /+}$ mouse blood, lung, spleen, and middle ear fluid. The percentage of $\mathrm{T}$ helper (Th) effector cells in the blood was significantly less in Fbxo11 $\mathrm{Jf/+}(0.69 \%)$ compared to the Jeff wildtype counterpart. The percentage of blood resting $\mathrm{T}$ cytotoxic cells was also significantly less in the Fbxo $11^{\mathrm{Jf} /+}(0.67 \%)$ compared to Jeff wild-type $(1.56 \%)$ mouse. In contrast, the percentage of blood $\mathrm{T}$ regulatory ( $\mathrm{T}$ reg) resting cells was significantly higher in the Fbxo11 $1^{J f /+}$ compared to Jeff wild-type mouse. The greatest difference was observed in the proportion of blood immature B cells; Fbxo11 $1^{\mathrm{Jf}+\mathrm{H}}$ had significantly less (9.26\%) immature B cells compared to the Jeff wild-type (21.98\%) mouse (Figure 2A-C). In contrast, NKT cell levels in the blood were significantly higher in the Fbxo11 $1^{\mathrm{If} / \mathrm{+}}$ compared to Jeff wild-type mouse. Fbxo11 $1^{\mathrm{If} / \mathrm{+}}$ mouse blood had a significantly higher level of effector NKT cells, 2.04\% compared to $0.77 \%$ in Jeff wild-type. A similar trend was observed in the levels of resting NKT cells and invariant NKT (iNKT) cells (Figure 1D-F, Table 1).
Analysis of cells derived from the lung did not show a significant difference in T-helper cells, but a significant reduction in the levels of naïve and resting $\mathrm{T}$-cytotoxic cells was observed in the Fbxo11 $1^{\mathrm{Jf} /+}$ compared to the Jeff wild-type mouse. The Fbxo $11^{\mathrm{Jf} /+}$ lung had 0.58 and $0.1 \%$ of naïve and resting $\mathrm{T}$ cytotoxic cells respectively compared to 1.25 and $0.44 \%$ (naive and resting respectively) in Jeff wild-type. Other than Tcytotoxic cells, the only significant reduction observed was in B2immature cells; the Fbxo $11^{\mathrm{ff} /+}$ lung had $5.14 \%$ of B2-immature cells compared to $8.52 \%$ in the Jeff wild-type mouse. The percent of effector Th cells was significantly lower $(0.72 \%)$ in Fbxo $11^{\mathrm{Jf} /+}$ compared to $1.28 \%$ observed in the Jeff wild-type mouse whereas the resting $\mathrm{T}$ reg percentage was significantly higher in $\mathrm{Fbxo1} 1^{\mathrm{Jf} / \mathrm{+}}$ spleen (1.34\%) compared to that found in Jeff wild-type (0.82\%). Also, a higher percentage of resting NKT cells was observed in Fbxo11 ${ }^{\mathrm{Jf} / \mathrm{+}}$ spleen $(1.63 \%)$ compared to its wild-type counterpart $(0.78 \%)$. In the middle ear fluid, the highest percentage of adaptive immune cells observed was NKT cells at $5.83 \%$; among these NKT cells nearly 55\% were effector cells. After NKT cells, B cells were the second highest adaptive immune cells observed in the Fbxo11 $1^{\mathrm{f} /+}$ mouse middle ear fluid. The percentages of $\mathrm{B} 1$ and $\mathrm{B} 2$ cells in the Fbxo $11^{\mathrm{Jf} /+}$ middle ear fluid were 1.74 and $1.37 \%$, respectively and nearly $75 \%$ of the B2 cells were mature (Table $\mathbf{1}$ ).

Similar analysis carried out on the Fbxo11 $1^{\text {tm2b/+ }}$ knockout mouse did not show major differences in adaptive immune cells as had been observed for the Fbxo1 $11^{\mathrm{f} / \mathrm{+}}$ mouse compared to the respective wild type (Table $\mathbf{S 3}$ ). Other than splenic immature B2 cells, no other significant differences were observed in the Fbxo11 $1^{\text {tm } 2 b /+}$ knockout compared to its wild-type counterpart Fbxo $11^{+/+}$mouse. The Fbxo $11^{\text {tm } 2 b /+}$ mouse spleen had a significantly higher proportion of immature B2 cells $(16.23 \%)$ compared to its wild-type counterpart $\mathrm{Fbxo11}^{+/+}(8.60 \%)$. Our analysis indicates that the mutation in the Fbxo11 $1^{\mathrm{ff}+}$ mouse affects not only the innate immune cell content but also adaptive

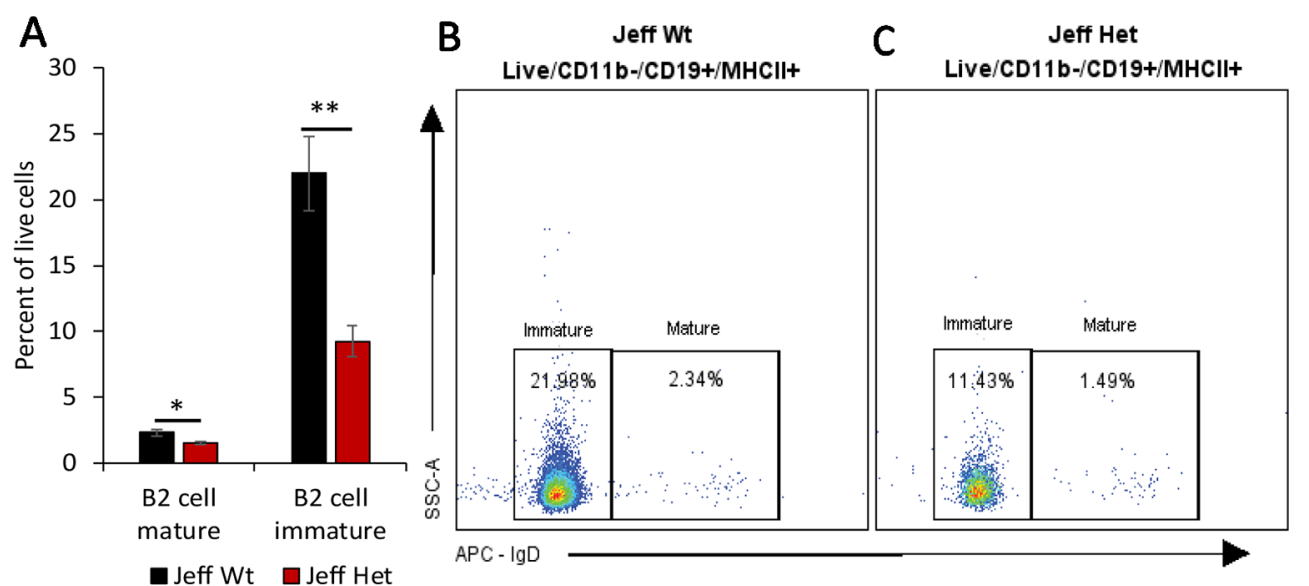

FIGURE 2 | B cell percentage in Jeff mice (Fbxo11 Jf/ and Jeff Wt). (A) Average difference in the percentage of mature and immature blood B2 cells in Jeff Het $\left(\right.$ Fbxo $11^{\mathrm{Jf} / \mathrm{+}}$ ) and Jeff Wt mice. The error bars show standard error of mean where $\mathrm{n}=4$ and ${ }^{*} \mathrm{P}<0.05$, ${ }^{\star *} \mathrm{P}<0.01$. Representative flow cytometry plot for $\mathrm{B}$ cell analysis of bloods from Jeff Wt (B) and Jeff Het $\left(\right.$ Fbxo11 $\left.{ }^{\mathrm{Jf} /+}\right)$ (C) mice. 
immune cells. The absence of cellular immune changes in the Fbxo11 $1^{\mathrm{tm} 2 b /+}$ mouse that were observed in the Fbxo11 $1^{\mathrm{ff} /+}$ mouse suggests that the ENU mutation in the Fbxo11 gene could be gain of function which alters the regulation of immune cells, leading to lung and middle ear phenotypes observed in the Fbxo1 $1^{\mathrm{Jf} /+}$ mice.

\section{Cytokine/Chemokine Levels in Jeff Mouse}

Mutation in the Fbxo11 gene leads to systemic and local differences in the Fbxo11 $1^{J f /+}$ mouse immune cells. To understand the influence of the autocrine and paracrine signals on the differences observed, levels of the specific cytokines/ chemokines that modulate the functional response in the immune cells were analyzed (Figure 3A). A significant increase in G-CSF, GM-CSF, sTNFRI (soluble TNFRI), and TPO levels was observed in the Fbxo $11^{\mathrm{Jf}+}$ serum compared to the Jeff wildtype. The significant increase in the NK cells observed in the Fbxo11 $1^{\mathrm{f} / \mathrm{+}}$ mouse could correlate with the major cytokines known to modulate NK cell number and function, IL-7 and IL-15 (Figure 3B). Of these two cytokines, only IL-7 was significantly higher in Fbxo11 $1^{\mathrm{ff} /}$ serum compared to its wildtype counterpart mouse. A majority of the cytokine/chemokines in the $F b x o 11^{I f /+}$ mouse middle ear fluid were relatively high: IL12p40/p70, IL-12p70, CCL2, sTNFRI, and TPO. High levels of IL-7 were also observed in the Fbxo $11^{\mathrm{Jf} /+}$ middle ear fluid.

\section{DISCUSSION}

One of the best characterized animal models for chronic OM is the Jeff mouse mutant, which carries a mutation in the Fbxo11 gene that is known to be associated with human OM (Hardisty et al., 2003; Segade et al., 2006; Bhutta et al., 2017a). To understand the effect of this mutation on the systemic and localized immune cell content, we analyzed the immune cell population in the Jeff mutant mouse.

The most significant difference observed between Jeff heterozygotes $\left(F b x o 11^{f f /+}\right)$ and wild-type mice was in the increased percentage of NK cells in blood, which are

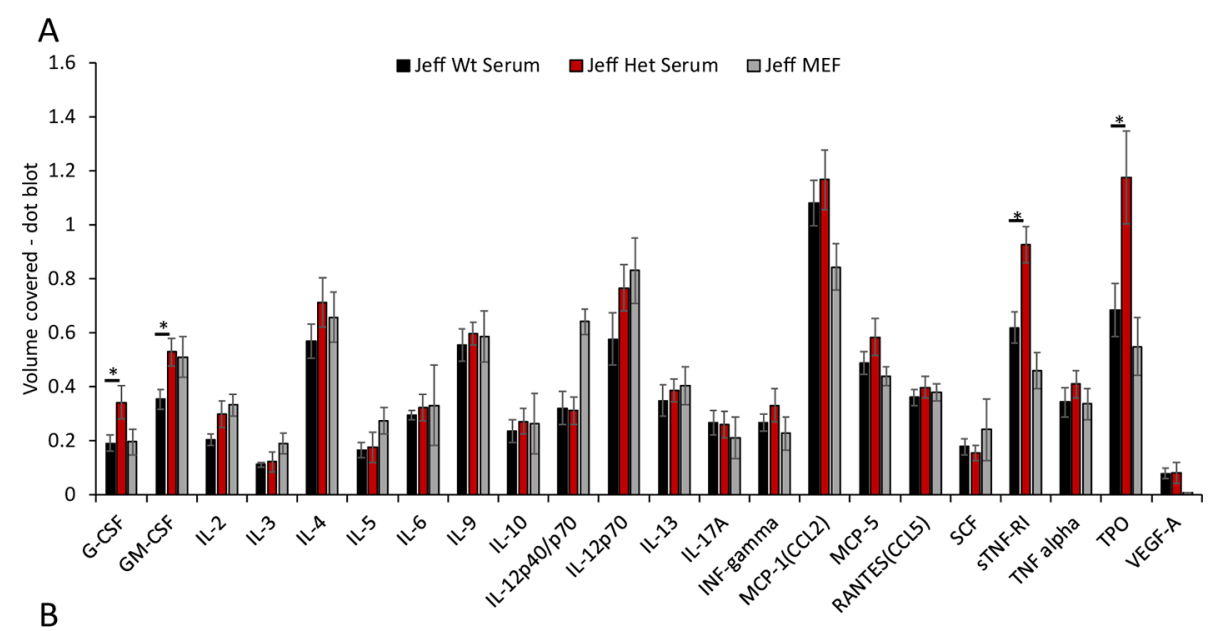

B

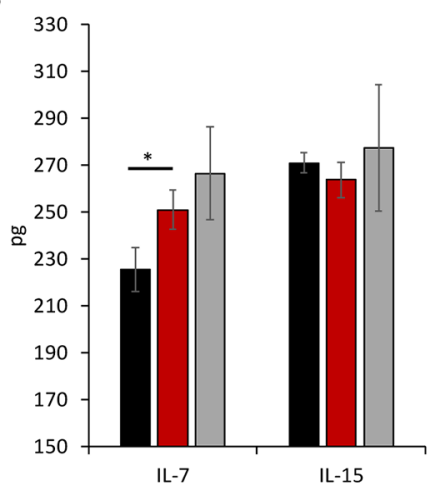

घeff Wt serum $\quad$ Jeff Het serum $\square$ Jeff MEF

FIGURE 3 | Cytokine and chemokine levels in Jeff mouse (Fbxo $11^{\mathrm{Jf} / \mathrm{t}}$ and Jeff $\mathrm{Wt}$ ) serum and middle ear fluid (MEF). (A) The volume coverage represents the cytokine/chemokine levels obtained after analyses of $10 \mu \mathrm{l}$ serum from Jeff Het $\left(F b \times 011^{\mathrm{Jt} / \mathrm{H}}\right)$ and Jeff Wt and $1 \mu \mathrm{l} \mathrm{MEF} \mathrm{from} \mathrm{Jeff} \mathrm{Het}\left(F b \times 011^{\mathrm{Jf} / \mathrm{H}}\right)$. Volume cover was calculated using Image Lab (BioRadTM) analysis on the RayBioRc C-Series mouse cytokine antibody array C1. (B) Interleukin (IL)-7 and IL-15 levels in the serum from Jeff Het (Fbxo $11^{\mathrm{Jf} /+}$ ) and Jeff Wt and MEF from Jeff Het (Fbxo $\left.11^{\mathrm{Jf} /+}\right)$, using mouse IL-7 or IL-15 DuoSet ELISA (R\&D systems ${ }^{\mathrm{TM}}$ ). The concentrations in pg/ml were obtained from the standard graph of concentration against absorbance at $450 \mathrm{~nm}$. The error bars show standard error of mean where $n=4$ and ${ }^{*} P<0.05$. 
significantly raised in the mutant. Similarly, the percentage of NKT cells (effector, resting, and iNKT) was high in the Fbxo $11^{\mathrm{Jf} /+}$ compared to the wild-type mouse. Analysis carried out on otitisprone children has shown similar findings; children prone to OM have a higher proportion of NK cells in blood compared to a healthy control group. The authors of the study postulate that the increase in NK cell numbers is due to prolonged exposure to upper respiratory tract infection (Seppanen et al., 2018). However, our current study provides the possibility of a genetic link being responsible for the increase in the circulating NK cells. The Fbxo $11^{\mathrm{Jf} /+}$ mice utilized in the present study are bred in specific pathogen-free conditions (Hood et al., 2016). The development of OM in Fbxo $11^{\mathrm{Jf} /+}$ mice is spontaneous at a young age (Hardisty et al., 2003). A similar analysis carried out in the Fbxo $11^{\text {tm } 2 b /+}$ knockout mouse did not show any difference in the NK cell population when compared to its wild-type counterpart. This indicates that the increase in the NK cells in the circulation can be purely attributed to the specific mutation in the Fbxol1 gene in the Fbxo11 $1^{\mathrm{f} / \mathrm{+}}$ mouse.

One of the major cytokines that plays a critical role in NK cell development, homeostasis, and activation is IL-15 (Marçais et al., 2013). Mice deficient in IL-15 do not produce NK cells, supporting its significance in NK cell development (Ranson et al., 2003). Analysis of IL-15 levels in the Fbxo11 ${ }^{\mathrm{Jf} / \mathrm{H}}$ mouse serum did not show a significant difference compared to its wildtype counterpart indicating that the Fbxo11 mutation does not affect the paracrine signaling for NK cell modulation through IL15. IL-15 maintains the peripheral NK cell numbers by increasing the anti-apoptotic BCL6 family proteins (Ranson et al., 2003). BCL6 is targeted for ubiquitination and proteasomal degradation by an SKP1-CUL1-F- box protein (SCF) ubiquitin ligase complex that contains the FBXO11 protein (Duan et al., 2012). The increased blood NK cell percentage in the Fbxo11 $1^{\mathrm{fl}+}$ mouse indicates the possible alteration of the SCF mediated BCL6 degradation, specifically in the NK cells. Another important cytokine that regulates NK cell function is TGF-beta, levels of which were not significantly different in the Fbxo11 $1^{\mathrm{ff}+\mathrm{H}}$ mouse compared to its wild-type counterpart. Earlier studies carried out on the Fbxo $11^{I f /+}$ mouse have highlighted the significance of the Jeff mutation on the Smad 2 mediated TGF-beta induced intracellular signaling in the developmental pathways (Tateossian et al., 2009). Even though we did not observe any significant difference in the levels of TGF-beta in the Fbxo11 $1^{J f /+}$ mouse, the intracellular signaling induced by TGF-beta in the NK cells could play a vital role in their increased levels and function.

Along with NK cells, we also observed a significant increase in the circulating $\mathrm{T}$ cell population in the Fbxo $11^{\mathrm{Jf/}}$ mouse. One of the cytokines that can stimulate the release of lymphocytes from bone marrow and thymus is IL-7 (von Freeden-Jeffry et al., 1995); levels of this cytokine were significantly higher in the Fbxo11 $1^{J f /+}$ serum compared to its wild-type counterpart. Along with increasing lymphocyte numbers, this elevated level of IL-7 can also result in increased thymic NK cell numbers (Marçais et al., 2013). IL-7 also increases the release of B cells from bone marrow and thymus (von Freeden-Jeffry et al., 1995) but in Fbxo11 $1^{\mathrm{Jf} /+}$ the percentage of B cells was significantly lower than in the wild-type mouse. FBXO11 is known to play a critical role in maintenance of B cell levels via the BCL6 pathway and FBXO11 loss of function is frequently observed in B cell lymphoma cell lines and increased B-cell levels (Duan et al., 2012), as we observed in the Fbxo11 ${ }^{\text {tmb2/+ }}$ knockout mouse. Restoration of BCL6 function in the B cell lymphoma cell lines has been shown to inhibit B-cell lymphogensis (Duan et al., 2012), indicating a potential critical role played by FBXO11 in the modulation of $\mathrm{B}$ cell survival. Our observation of reduced levels of B cells in the Fbxo11 $1^{\mathrm{Jf} /+}$ mouse indicates that the Jeff mutation in the B-cells could be inducing the apoptotic pathways, possibly through BCL6. This novel role of Fbxo11 in the modulation of B cell survival warrants further studies but suggest that the Jeff mutation may be manifesting gain of function phenotypes in the regulation of B cell numbers.

The other cytokines that were significantly increased in the Fbxo $11^{\mathrm{Jf} / \mathrm{t}}$ serum compared to wild-type were G-CSF and GM-CSF. Both these cytokines play a critical role in the regulation of neutrophil development (Roberts, 2005), which could correspond with the significantly higher blood granulocyte levels observed in the Fbxo11 $1^{J f /+}$ mouse. G-CSF also inhibits NK cell activity (Schlahsa et al., 2011). IL-2 is one of the major cytokines released after activation of NK cells. In the Fbxo1 $1^{\mathrm{Jf}+\mathrm{H}}$ mouse, even with the high percentage of NK cells in the circulation, no difference in IL-2 levels was observed compared to wild type. Neutrophil numbers also play a critical role in perturbation of inflammation in the middle ear. In other animal models, the extracellular neutrophil DNA in the middle ear fluid contributes to NTHi biofilm formation (Jurcisek and Bakaletz, 2007; Juneau et al., 2011). In the case of Fbxo $11^{f f /+}$ mice, the neutrophil percentage in the middle ear fluid was high and most of these were living. This might be a contributing factor toward the significantly lower NTHi titers and infection rate observed in Fbxo11 $1^{\mathrm{ff}+\mathrm{+}}$ compared to Junbo mice (Hood et al., 2016); the latter has high levels of necrotic cells in the middle ear fluid (Vikhe et al., 2019).

The level of soluble TNFRI (sTNFR1) in the Fbxo $11^{\mathrm{Jf} / \mathrm{t}}$ serum was significantly higher than that found in wild-type, whereas TNF-alpha levels were not different. sTNFRI has a high affinity for TNF-alpha (Wang et al., 2004), modulating its slow release and thus suppressing inflammation. It is well established that inhibiting TNF-alpha decreases middle ear inflammation in OM (Jeun et al., 2001). Trans-tympanic membrane treatment of mice with sTNFRI and anti-TNF-alpha inhibits LPS induced middle ear inflammation and OM (Jeun et al., 2001). The molecular level regulation for the release of sTNFRI is still unclear. The increase in sTNFRI in the Fbxo11 $1^{\mathrm{f} / \mathrm{+}}$ mouse serum indicates a role for FBXO11 in its regulation; this mouse model could play an essential role in understanding the regulation of this critical cytokine at the genetic level.

Another cytokine/growth factor that was significantly higher in Fbxo11 $1^{\mathrm{f} / \mathrm{+}}$ mouse serum was thrombopoietin (TPO). TPO is a growth factor that initiates the process of megakaryocyte production and generation of platelets (Lupia et al., 2012). 
Increased levels of TPO are found in patients with inflammatory bowel disease (Kapsoritakis et al., 2000) and Streptococcus pneumoniae induced bacterial meningitis in mice (Hoffmann et al., 2011). The relevance of TPO in cardiovascular damage and inflammatory diseases is known (Lupia et al., 2012), but its role in $\mathrm{OM}$ has yet to be evaluated. We were not able to classify platelet population in the Fbxo $11^{J f /+}$ mouse in our current study but increased levels of TPO are indicative of abnormal platelet function and its relevance in OM can be investigated using this mutant mouse model.

In conclusion, our studies of the Jeff $\left(F b x o 11^{\mathrm{Jf} /+}\right)$ mouse model identify immune cell changes which can play a critical role in inflammation. A significant increase in blood neutrophil, NK cells, NKT cells and dendritic cells were observed in the Fbxo $11^{\mathrm{ff} /+}$ mutant mouse compared to wild-type. The heterozygote Fbxo11 knockout mouse did not show these differences, consistent with a gain of function for the Jeff mutation that leads to these immune cell changes. Interestingly, as we report elsewhere (Kubinyecz et al. manuscript submitted), the Fbxo1 ${ }^{\text {tm } 2 b /+}$ heterozygous knockout mouse does not develop a spontaneous OM phenotype as observed in $F b x o 11^{\mathrm{Jf}+}$, which is also indicative of gain of function effects. In conclusion, this study paves the way for further studies using the Jeff model to dissect the genetic interrelationships between the control of immune cells and OM.

\section{DATA AVAILABILITY STATEMENT}

All datasets generated for this study are included in the article/ Supplementary Material.

\section{ETHICS STATEMENT}

The animal study was reviewed and approved by MRC Harwell Institute ethics review committee and this study was carried out under the appropriate UK Home Office license.

\section{REFERENCES}

Abida, W. M., Nikolaev, A., Zhao, W., Zhang, W., and Gu, W. (2007). FBXO11 promotes the Neddylation of $\mathrm{p} 53$ and inhibits its transcriptional activity. J. Biol. Chem. 282, 1797-1804. doi: 10.1074/jbc.M609001200

Bhutta, M. F., Lambie, J., Hobson, L., Goel, A., Hafrén, L., Einarsdottir, E., et al. (2017a). A mouse-to-man candidate gene study identifies association of chronic otitis media with the loci TGIF1 and FBXO11. Sci. Rep. 7, 18-24. doi: 10.1038/s41598-017-12784-8

Bhutta, M. F., Thornton, R. B., Kirkham, L.-A. S., Kerschner, J. E., and Cheeseman, M. T. (2017b). Understanding the aetiology and resolution of chronic otitis media from animal and human studies. Dis. Model. Mech. 10, 1289-1300. doi: 10.1242/ dmm.029983

Crompton, M., Purnell, T., Tyrer, H. E., Parker, A., Ball, G., Hardisty-Hughes, R. E., et al. (2017). A mutation in Nischarin causes otitis media via LIMK1

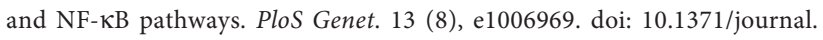
pgen.1006969

Duan, S., Cermak, L., Pagan, J. K., Rossi, M., Martinengo, C., Celle, F., et al. (2012). FBXO11 targets BCL6 for degradation andis inactivated in diffuse large B-cell lymphomas. Nature. 481, 90-94. doi: 10.1038/nature10688

\section{AUTHOR CONTRIBUTIONS}

PV designed and conceptualized the experiments. PV, HT, and GB performed the experiments. PV, and GB analyzed the data. PV and HT participated in collecting animals testes. PV drafted the manuscript. PV, HT, DH, and SB edited and wrote the final manuscript. All authors approved the manuscript for submission.

\section{FUNDING}

This work was funded by the Medical Research Council (MRC funding award no. MC_U142684175).

\section{ACKNOWLEDGMENTS}

We thank the staff in the Mary Lyon Centre for the husbandry and humane care of these mice, clinical chemistry, pathology and histology teams, and the genotyping core, at MRC Harwell Institute.

\section{SUPPLEMENTARY MATERIAL}

The Supplementary Material for this article can be found online at: https://www.frontiersin.org/articles/10.3389/fgene.2020. 00050/full\#supplementary-material

FIGURE S1 | Flow cytometry panel 1 gating strategy.

FIGURE S2 | Flow cytometry panel 2 gating strategy.

TABLE S1 | Flow cytometry antibody and panels.

TABLE S2 | Flow cytometry gating strategy.

TABLE S3 | Immune cell percentage in Fbxo1 $1^{\text {tmb2/+ }}$ (Fbxo11 knockout) and $\mathrm{Fb} \times 11^{+/+}$mouse obtained by flow cytometry.

Hardisty, R. E., Erven, A., Logan, K., Morse, S., Guionaud, S., Sancho-Oliver, S., et al. (2003). The deaf mouse mutant Jeff (Jf) is a single gene model of otitis media. J. Assoc. Res. Otolaryngol. 4, 130-138. doi: 10.1007/S10162-002-3015-9

Hardisty-Hughes, R. E., Tateossian, H., Morse, S. A., Romero, M. R., Middleton, A., Tymowska-Lalanne, Z., et al. (2006). A mutation in the F-box gene, Fbxo11, causes otitis media in the Jeff mouse. Hum. Mol. Genet. 15, 3273-3279. doi: 10.1093/hmg/ ddl 403

Hoffmann, O., Rung, O., Im, A.-R., Freyer, D., Zhang, J., Held, J., et al. (2011). Thrombopoietin contributes to neuronal damage in experimental bacterial meningitis. Infect. Immun. 79, 928-936. doi: 10.1128/IAI.00782-10

Hood, D., Moxon, R., Purnell, T., Richter, C., Williams, D., Azar, A., et al. (2016). A new model for non-typeable Haemophilus influenzae middle ear infection in the Junbo mutant mouse. Dis. Model. Mech. 9, 69-79. doi: 10.1242/dmm.021659

Jeun, E.-J., Park, Y.-S., Yeo, S. W., Choi, Y.-C., and Jung, T. T. K. (2001). Effect of inhibitor of tumor necrosis factor-alpha on experimental otitis media with effusion. Ann. Otol. Rhinol. Laryngol. 110, 917-921. doi: 10.1177/ 000348940111001005

Juneau, R. A., Pang, B., Weimer, K. E. D., Armbruster, C. E., and Swords, W. E. (2011). Nontypeable Haemophilus influenzae initiates formation of neutrophil extracellular traps. Infect. Immun. 79, 431-438. doi: 10.1128/IAI.00660-10 
Jurcisek, J. A., and Bakaletz, L. O. (2007). Biofilms formed by nontypeable Haemophilus influenzae in vivo contain both double-stranded DNA and type IV pilin protein. J. Bacteriol. 189, 3868-3875. doi: 10.1128/JB.01935-06

Kapsoritakis, A. N., Potamianos, S. P., Sfiridaki, A. I., Koukourakis, M. I., Koutroubakis, I. E., Roussomoustakaki, M. I., et al. (2000). Elevated thrombopoietin serum levels in patients with inflammatory bowel disease. Am. J. Gastroenterol. 95, 3478-3481. doi: 10.1111/j.1572-0241.2000.03364.x

Li, J.-D., Hermansson, A., Ryan, A. F., Bakaletz, L. O., Brown, S. D., Cheeseman, M. T., et al. (2013). Panel 4: recent advances in otitis media in molecular biology, biochemistry, genetics, and animal models. Otolaryngol. Head. Neck Surg. 148, E52-E63. doi: 10.1177/0194599813479772

Lupia, E., Goffi, A., Bosco, O., and Montrucchio, G. (2012). Thrombopoietin as biomarker and mediator of cardiovascular damage in critical diseases. Mediators Inflamm. 2012, 1-12. doi: 10.1155/2012/390892

Marçais, A., Viel, S., Grau, M., Henry, T., Marvel, J., and Walzer, T. (2013). Regulation of mouse NK cell development and function by cytokines. Front. Immunol. 4, 450. doi: 10.3389/fimmu.2013.00450

Mittal, R., Kodiyan, J., Gerring, R., Mathee, K., Li, J.-D., Grati, M., et al. (2014). Role of innate immunity in the pathogenesis of otitis media. Int. J. Infect. Dis. 29, 259-267. doi: 10.1016/j.ijid.2014.10.015

Nolan, P. M., Peters, J., Strivens, M., Rogers, D., Hagan, J., Spurr, N., et al. (2000). A systematic, genome-wide, phenotype-driven mutagenesis programme for gene function studies in the mouse. Nat. Genet. 25, 440-443. doi: 10.1038/78140

Parkinson, N., Hardisty-Hughes, R. E., Tateossian, H., Tsai, H. T., Brooker, D., Morse, S., et al. (2006). Mutation at the Evil locus in Junbo mice causes susceptibility to otitis media. PloS Genet. 2, 1556-1564. doi: 10.1371/ journal.pgen.0020149

Ranson, T., Vosshenrich, C. A. J., Corcuff, E., Richard, O., Müller, W., and Di Santo, J. P. (2003). IL-15 is an essential mediator of peripheral NK-cell homeostasis. Blood 101, 4887-4893. doi: 10.1182/blood-2002-11-3392

Roberts, A. W. (2005). G-CSF: a key regulator of neutrophil production, but that's not all! Growth Factors 23, 33-41. doi: 10.1080/08977190500055836

Rye, M. S., Wiertsema, S. P., Scaman, E. S. H., Oommen, J., Sun, W., Francis, R. W., et al. (2011). FBXO11, a regulator of the TGF $\beta$ pathway, is associated with severe otitis media in Western Australian children. Genes Immun. 12, 352-359. doi: 10.1038 /gene.2011.2

Sale, M. M., Chen, W.-M., Weeks, D. E., Mychaleckyj, J. C., Hou, X., Marion, M., et al. (2011). Evaluation of 15 functional candidate genes for association with chronic otitis media with effusion and/or recurrent otitis media (COME/ ROM). PloS One 6, e22297. doi: 10.1371/journal.pone.0022297

Schilder, A. G. M., Chonmaitree, T., Cripps, A. W., Rosenfeld, R. M., Casselbrant, M. L., Haggard, M. P., et al. (2016). Otitis media. Nat. Rev. Dis. Prim. 2, 16063. doi: 10.1038/nrdp. 2016.63

Schlahsa, L., Jaimes, Y., Blasczyk, R., and Figueiredo, C. (2011). Granulocytecolony-stimulatory factor: a strong inhibitor of natural killer cell function. Transfusion 51, 293-305. doi: 10.1111/j.1537-2995.2010.02820.x

Segade, F., Daly, K. A., Allred, D., Hicks, P. J., Cox, M., Brown, M., et al. (2006). Association of the FBXO11 gene with chronic otitis media with effusion and recurrent otitis media: the Minnesota COME/ROM Family Study. Arch. Otolaryngol. Head. Neck Surg. 132, 729-733. doi: 10.1001/archotol.132.7.729

Seppanen, E., Tan, D., Corscadden, K. J., Currie, A. J., Richmond, P. C., Thornton, R. B., et al. (2018). Evidence of functional cell-mediated immune responses to nontypeable Haemophilus influenzae in otitis-prone children. PloS One 13, e0193962. doi: 10.1371/journal.pone.0193962

Tateossian, H., Hardisty-Hughes, R. E., Morse, S., Romero, M. R., Hilton, H., Dean, C., et al. (2009). Regulation of TGF- $\beta$ signalling by Fbxo11, the gene mutated in the Jeff otitis media mouse mutant. Pathogenetics 2, 5. doi: 10.1186/ 1755-8417-2-5

Tateossian, H., Morse, S., Simon, M. M., Dean, C. H., and Brown, S. D. M. (2015). Interactions between the otitis media gene, Fbxol1, and p53 in the mouse embryonic lung. Dis. Model. Mech. 8, 1531-1542. doi: 10.1242/ dmm.022426

Veenhoven, R., Bogaert, D., Uiterwaal, C., Brouwer, C., Kiezebrink, H., Bruin, J., et al. (2003). Effect of conjugate pneumococcal vaccine followed by polysaccharide pneumococcal vaccine on recurrent acute otitis media: a randomised study. Lancet 361, 2189-2195. doi: 10.1016/S0140-6736(03) 13772-5

Vikhe, P. P., Purnell, T., Brown, S. D. M., and Hood, D. W. (2019). Cellular content plays a crucial role in Non-typeable Haemophilus influenzae infection of preinflamed Junbo mouse middle ear. Cell. Microbiol. 21, 1-11. doi: 10.1111/ cmi. 12960

von Freeden-Jeffry, U., Vieira, P., Lucian, L. A., McNeil, T., Burdach, S. E., and Murray, R. (1995). Lymphopenia in interleukin (IL)-7 gene-deleted mice identifies IL-7 as a nonredundant cytokine. J. Exp. Med. 181, 1519-1526. doi: $10.1084 / \mathrm{jem} .181 .4 .1519$

Wan, Y. Y., and Flavell, R. A. (2007). Yin-Yang functions of transforming growth factor-beta and T regulatory cells in immune regulation. Immunol. Rev. 220, 199-213. doi: 10.1111/j.1600-065X.2007.00565.x

Wang, M., Meng, X., Tsai, B., Wang, J.-F., Turrentine, M., Brown, J. W., et al. (2004). Preconditioning up-regulates the soluble TNF receptor I response to endotoxin. J. Surg. Res. 121, 20-24. doi: 10.1016/j.jss.2004.02.017

Zheng, H., Shen, M., Zha, Y.-L., Li, W., Wei, Y., Blanco, M. A., et al. (2014). PKD1 phosphorylation-dependent degradation of SNAIL by SCF-FBXO11 regulates epithelial-mesenchymal transition and metastasis. Cancer Cell 26, 358-373. doi: 10.1016/J.CCR.2014.07.022

Conflict of Interest: The authors declare that the research was conducted in the absence of any commercial or financial relationships that could be construed as a potential conflict of interest.

Copyright $\odot 2020$ Vikhe, Tateossian, Bharj, Brown and Hood. This is an open-access article distributed under the terms of the Creative Commons Attribution License (CC $B Y)$. The use, distribution or reproduction in other forums is permitted, provided the original author(s) and the copyright owner(s) are credited and that the original publication in this journal is cited, in accordance with accepted academic practice. No use, distribution or reproduction is permitted which does not comply with these terms. 